\title{
Omnichannel Value Chain: Mapping Digital Technologies for Channel Integration Activities
}

\author{
Rehan Iftikhar, Zohreh Pourzolfaghar and Markus Helfert
}

\begin{abstract}
To provide a seamless customer experience across different channels, researchers and practitioners have proposed the creation of an omnichannel retailing environment by integrating online and offline retail channels. However, retailers are struggling with the selection and implementation of suitable technologies to add value through channel integration. Despite the strong practical need, this issue has not been effectively addressed in the academic literature. This paper introduces an omnichannel value chain model underpinned by Porter's value chain and presents ten channel integration activities for value creation by carrying out a comprehensive synthesis of current research on omnichannel retailing. We also identify the technology related challenges faced by retailers in the execution of these channel integrating activities drawing upon a case study with an Irish retailer. Enabling digital technologies are then mapped to these activities that provide a guideline for retailers to select appropriate technologies for the value creation activities.
\end{abstract}

Keywords: Channel Integration · Omnichannel Retail · Digital Technologies · Value Chain · Technology Mapping

A prior version of this paper has been published in the ISD2019 Proceedings (http://aisel.aisnet.org/isd2014/proceedings2019).

R. Iftikhar $(\bowtie)$

Maynooth University, Maynooth, Ireland

e-mail: rehan.iftikhar@mu.ie

Z. Pourzolfaghar

Maynooth University, Maynooth, Ireland

e-mail: zohreh.pourzolfaghar@mu.ie

M. Helfert

Maynooth University, Maynooth, Ireland

e-mail: markus.helfert@mu.ie

(C) Springer International Publishing Switzerland 2020

A. Siarheyeva et al. (eds.), Advances in Information Systems Development - Information Systems Beyond 2020

Lecture Notes in Information Systems and Organisation, $\mathrm{XX}$

DOI XX.XXXX/XXXXXXX 


\section{$1 \quad$ Introduction}

The retail sector is experiencing an influx of innovative methods and technologies to enhance and reform the customer experience [58]. Along with this influx, there has been a huge change in information technology (IT) provision, technology cost, and access to technology. These changes are affecting the way value creation activities are performed and the nature of the linkages among them. It is pushing the retail sector toward a new digital path i.e. omnichannel retailing [51]. Omnichannel retailing is the synergic offering of all available channels and customer touchpoints to optimize customer experience and performance across channels [51].

The most significant characteristic of omnichannel retailing is channel integration [36]. Channel integration has been shown to have a positive effect on customer experience and acts as a competitive advantage for retailers [23] which leads to stronger sales growth [14], an increase in the "perceived quality of the channels" [35] and the reduction of service inconsistencies [67]. Additionally, channel integration can achieve synergies such as "improved customer trust, improved customer awareness, consumer risk reduction, and coverage of diverse shopping preferences" [24]. Furthermore, it allows retailers to actively maintain customer contact and develop a proactive customer experience management strategy through increased customer insights [67]. Finally, the interconnection of channels makes it harder for competitors to imitate the company. It could increase the customer's value proposition and thus reduces the competitive pressure [24]. Despite all the above mentioned benefits of channel integration, retailers are still not developed enough in terms of application and implementation of technology to achieve completely integrated channels and create desired value [19, 45, 54].

Technology implementation for channel integration is a major undertaking because of constantly evolving capabilities to drive the integration [67]. Retailers trying to adopt these technologies for channel integration can easily get lost by the variety of technologies to choose from [65]. Consequently, they often select technologies without examining the potential contributions to their strategies [31]. Extant literature on channel integration addressing the issues of technology implementation or technology capabilities in retail has mainly focused on the use of some specific technologies such as RFID $[2,3]$, augmented reality [25], beacons [50], mobile technologies [43, 62] etc. The literature which studies multiple technologies has either focused on physical stores or online shops. For example, [44] studies the intention of customers in using the fitting room and in-store technologies in an omnichannel physical store. Similarly, [5] and [10] investigated the use of in-store digital technologies, in order to enhance the customer experience in retail stores. [43] identifies aspects of omnichannel retailing which mobile technologies can affect while [3] and [2] studied the use of RFID as an enabler for channel integration. But a clear and comprehensive picture of the digital technologies that may be adopted to create value through different aspects of channel integration and their respective roles has yet to be revealed [54]. In this paper, we will try to address this research gap by first providing a framework of value creation activities in omnichannel and then mapping the enabling digital technologies to these activities.

For omnichannel retailing to be effective and efficient, multiple channel integration activities play a pivotal role [15]. Several technologies can enable the value creation 
through these activities but the implementation of any technology must be guided by business value creation [15]. We, therefore, identify activities in channel integration that are necessary for value creation in omnichannel retailing underpinned by Porter's value chain model [52] and then map to these activities the digital technologies which facilitate value creation by an extensive review of the literature and real world implementation examples. Hence, this paper adds to the literature by presenting an omnichannel value chain model and mapping of the enabling technologies to the identified value creation activities.

The remainder of this paper is structured as follows. First, in section two, we introduce the research methodology followed in the presented research. Afterward, in section three, we present channel integration activities that create value for omnichannel retailers and discuss the challenges in the execution of these activities. In section four, we describe enabling technologies for channel integration and real world examples of services using these technologies. In section five, we discuss the contribution and managerial implications of this study. Finally, we conclude the paper by summarizing our study and establishing scope for further research.

\section{Research Methodology}

For the mapping of digital technologies to value creation activities of channel integration, we followed a multi-phase research process. First, we conducted a literature review to identify channel integration activities in omnichannel retailing. We followed the approach for the literature review proposed by [64] and [13]. We defined the scope and goal of the review in identifying the value adding activities for an integrated retail system. We applied the search using keywords channel integration, omnichannel, technology and retail in three different databases for maximum coverage of omnichannel retailing literature i.e. Scopus, Science Direct and Web of Science. We used different combinations from the keywords to better understand the occurrence of the results such as ("omnichannel" OR "omni-channel") AND ("management" or "technology"), ("channel integration" OR "integrated channels") AND ("management" OR "technology") AND "retail". This search resulted in total of 635 articles. Afterward, we excluded duplicates, articles not published in English and published before 2012. We only considered literature after 2012 as the term 'omnichannel' was coined in literature in 2011 by [53] and most of the research related to channel integration for omnichannel retailing has been published after that.

Subsequently, we examined the sum of identified articles to evaluate whether the articles could contribute to this paper and excluded articles not topic-related, for example, articles regarding foreign market channel integration. We also excluded articles from unrelated disciplines to this research such as refrigeration science and technology, chemistry, applied mechanics, etc. After screening the remaining articles for the contribution to the study, 29 articles were selected, which were then used for defining the channel integration activities for value creation.

In the second phase, we conducted a case study to identify the challenges faced by retailers who are transitioning from multichannel to omnichannel retail. In line with the 
recommendations from Yin [68] for choosing the case according to pre-defined sample criteria. The retailer was selected which met the criteria of currently transitioning from multichannel to omnichannel. The case retailer (called 'CR' thereafter) is an Irish company with brick and mortars as their starting point around 50 years ago. They launched their online channel in 2010. Physical stores are currently managed independently from the webshop but the company is currently looking to integrate its channels in order "to create a seamless customer experience". We followed a multi-method data gathering strategy for the case study combining interviews, observation and secondary sources [68]. We conducted semi-structured and unstructured interviews with the Strategy Director, E-Commerce Director, Marketing Manager, the Web Store Manager, the Logistics Head, Head of Store Operations and the Store Manager. In total, 8 interviews were carried out with all the CR employees. The topics addressed concerned the challenges in the implementation of the omnichannel strategy, from the point of view of each interviewee's position. All interviews lasted between 60 to 150 minutes. We transcribed the semi-structured interviews while the non-structured interviews were summarized. For triangulation, we used secondary sources including financial reports, website and social media pages of the retailer. In this data collection process, we followed the principles suggested by [68] to guarantee the reliability and validity of the research. A thematic analysis was conducted manually to map the challenges faced by CR for the value creation activities identified in the first phase.

In the third phase, we identified the technologies which support the channel integration activities using literature and real world usage examples to explain their implementation. For the initial selection of enabling technologies for channel integration, a literature review was conducted. The results of the search phrase ('retail' and 'technology') were analyzed to find retail technologies for channel integration activities. The search resulted in 2280 articles. We performed text analysis on these articles using NVivo to uncover potential enabling technologies for channel integration. Only those technologies were selected which were mentioned at least five times in the identified articles to support one or more channel integration activities. To improve the reliability of our analysis, we also asked retail technology experts, who are currently working in the implementation of different technology solutions in retail, to come up with a final list of technologies to be analyzed. To complement our analyses, we also used examples of the actual implementation of these technologies to better comprehend the roles of the identified technologies [4]. We mapped the technologies to relevant channel integration activities. The technology mapping has been based on [22]. We recognized the major characteristics of the particular technologies and then identified characteristics enabling the value creation activities identified in the first phase for channel integration.

\section{Value Creation through Channel Integration}

Channel integration is the extent to which channels share common organizational activities as defined in Porter's value chain [52], including marketing, sales, operations, services, and logistics [69]. This leads to channel synergy, which necessitates the use of channels in such a way that the effectiveness of each separate channel increases in 
providing a seamless shopping experience for the customer. Channel synergy requires organizations to communicate and leverage the brand consistently across all channels [36]. Retailers have to facilitate a system where customers should be able to perceive the company as one entity and be offered various channel options that are seamlessly linked [51]. Based on the literature review, channel integration activities required for transformation to fully integrated omnichannel retail are introduced in the following sub-sections. These activities are presented in the omnichannel value chain model shown in Fig. 1. Challenges faced by the retailer in the case study for exaction of the identified activities are also described.

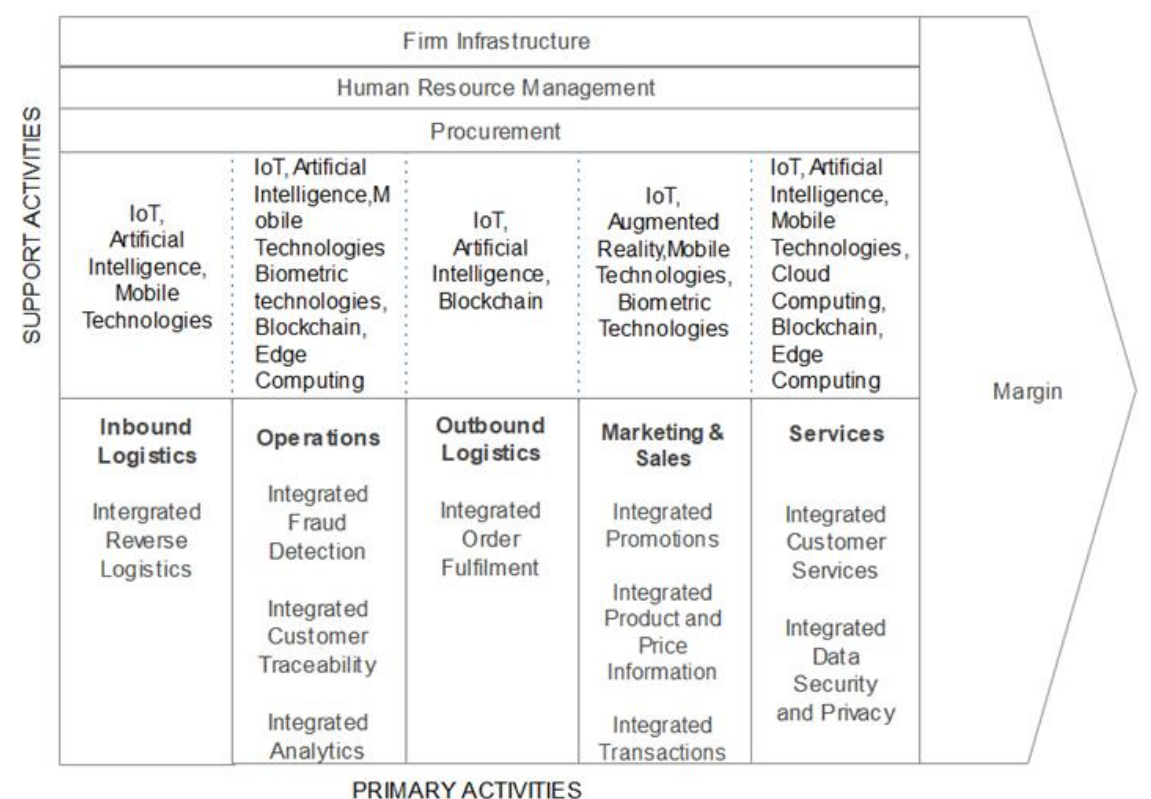

Fig. 1. Omnichannel Value Chain Model

\subsection{Integrated Customer Service}

Customer service integration refers to improving and enriching an interaction with a customer by blending the interaction simultaneously with other channels [11, 28]. Around 85 percent of customers who are not able to accomplish what they need in one channel such as a website will switch to other channels such as phone, mobile app, web chat, social media or email [28]. In-store customer service associates can use devices such as tablets and smartphones to provide enhanced customer service, for example by looking up information through the system to assist the consumer, thus reinforcing brand values and delivering a good shopping experience [11]. To provide in-store experience online, retailers can offer services such as virtual fitting room based on virtual reality. Fits.me is a virtual reality application used by several fashion brands (such as 
Hugo Boss, Twin-Set and Thomas Pink) to provide online shoppers with service which is traditionally only available in stores [41]. It offers a virtual fitting room for online shopping and suggests the garment size that is the closest match to the shopper's measurements, and enables the user to 'try on' several sizes to identify the preferred size and fit [41]. Similarly, to provide a digital experience in the physical store, services such as "on-screen customization" can be used. For instance, digitally enhanced stores such as Nike Town provide screens to customize one's shoes [11]. Similarly, customer service can be improved in social media channels by utilizing services associated to retailers' website using applications such as eBay ShopBot, which deals with consumer search enquiries on Facebook messenger and a variation of the application is now available on the Google Home device.

CR is a customer-centric company. According to their Strategy Director, "Customers are at the heart of what [CR] does. So the main thing and every decision we make is based off whether it's going to add to customer experience and if the customer is going to come back to us so growing our customer base and appreciating that and having an experiential customer experience that they want to come back to is probably number one at the top of things that we do." Being successful with this approach in their physical stores, now CR is finding it hard to exhibit similar levels of customer service in their online channels. The company recognizes this as a big challenge and their Strategy Director noted "Our customer-centricity doesn't come across in our online sites. You will not get that whole customer feel or that feel that the person is as invested in the customer as you will get if you spoke to a customer in the store. It's very different and hard to capture online."

\subsection{Integrated Customer Traceability}

When moving from one channel to the other, integrated customer traceability gives retailers the ability to maintain context and data continuity as the customer is moving from one channel to another channel $[9,34]$. Retailers can trace the customer journey started online and finished with an offline sale [9] using mobile technologies with services such as Google's offline sales conversion tool. Retailers can track the customer who explores a product offline and then buys online [9] using Google URL Builder. Using mobile ID tracking, retailers can use the consumers' smartphone's Wi-Fi to track their journey in the store and can know the repeat visitor and analyze the departments and parts of the store visited. Mobile Decision Support System can be used to check and compare reviews posted by consumers themselves and to extract reputations of a product from weblogs [21]. While retailers track customers across channels, they collect, store, analyze and transfer a lot of personal data from customers. In doing so, they face the challenge of protecting this data from breaches [46].

CR has started to put more emphasis on connecting the customer across different channels but is struggling with technology implementation. The marketing manager noted, "We are trying to do that [add shopping links to Instagram] but we're hitting a lot of hurdles." Similarly connecting the physical store customer to online channel has been a challenge especially with the implementation of GDPR. Web-store Manager explains this issue saying "We have thousands of tourist [customers] in our different 
stores. So we want to try and capture their information as best we can. With GDPR obviously, we lost a big bit from our database."

\subsection{Integrated Order Fulfilment}

Traceability and changeability of inventory, orders and delivery points during all stages of order fulfillment across all channels is required for a fully integrated omnichannel system $[29,55]$. In an integrated environment, a retailer needs to be able to see inventory across channels, that it knows where products are available and how fast it can get them to customers. With integrated order fulfillment, customers should be able to reserve products in the store using a mobile phone, web or social media (Reserve and Collect) [29] and collect products bought using mobile phone, web or social media in the physical store (Click and Collect) [39]. Customer can use their devices to reorder a product like Amazon Dash Button [29] and orders can be delivered to their place of choice in real-time like a car trunk using services such as Amazon Key delivery. Similarly, customers' needs can be predicted to have most of their regular buy in the store ready to be ordered online [59].

$\mathrm{CR}$ has invested in acquiring inventory systems to integrate their inventory across all channels. Logistic managers noted that the inventory system is updated very quickly across channels and said "... when it's all working fine within 30 seconds to a minute your [inventory system] should be updated. So, it is pretty much in real-time.” But they are looking to improve further in this regard. Head of Store Operations addressing a good practice she experienced at another store said, "I was in a store recently where I was looking for an item and she [sales assistant] said, what are you looking for? And I said, Oh, do you have that in whatever size and she said not in the store but before I knew it, 10 seconds later, my card was in the back of an IPad, it was delivered to my house the following morning. That's what I want."

\subsection{Integrated Transactions}

Providing secure access to complete the transaction via all available channels constitutes integrated transactions. Regardless of how, where and within which channel the transaction is made, the relevant data should be securely retrievable by other parties in the integrated transaction system [55]. With integrated transactions, customers should be able to purchase products directly from all available channels e.g. social media outlets of the retailer and to purchase products directly from an advertisement on any channel e.g. TV or news advertisement, digital signage, catalog. Customers should be able to check out without going through a physical check out desk using other channels for payment in store e.g. Amazon Go, Mobile and Tablet check out [29], thus adding value to marketing activities of the retailer.

CR management has recognized that integrated transactions are an important part of the transition to omnichannel retail. Head of Store Operations with regards to opportunities for integrated transactions noted "I want to have iPads that I can flip over and people can pay. I want to be in a position where we don't have to bring a customer to a till all the time as well, as its too formal...I want to have something that I can use on the 
shop floor that they can just put their card into and just get that sale." Strategy Director mentioned on the similar lines saying "we are looking at Amazon pay actually. so they just come into Ireland recently, they want to pilot with us. So they would be someone we'd be looking at because again, they have a lot to offer, I think in terms of the checkout and how to improve us in that whole space. So I think that's an opportunity."

\subsection{Integrated Product and Price Information}

Integrated pricing and product information implies synchronization of the products' description, stock status, prices, and makes changes in them (e.g. discounts, availability) visible for consumers and other members of the omnichannel system instantly [55, 63]. This integration should also pick up on any mistake, mismatch, or absence of product data anywhere in the omnichannel system, and initiate the necessary corrective actions [55]. Shopify and Google's direct integration makes it easy for shoppers to discover products available in-store with Google Smart Shopping campaigns. Another example of an online-to-offline relationship is Sephora mobile application [48]. Digitally enhanced stores such as Nike Town are providing i-Kiosks to look up information digitally [11]. Retailers should also provide information based on customer social networks via different digital channels [29].

CR has adopted generally an integrated pricing strategy for its online and offline channels. As customers are now able to access online information easily when they are in physical stores, the pricing and product information needs to be consistent. But CR is struggling with providing additional information in stores such as videos which they are providing to online customers. The words of Head of Store Operations in describing this scenario were "so much technology goes into websites and what we do online and all that I think we don't have enough technology in the store to provide details around products to our customers." But on the other side, information about products is lacking on the website as well. CR is now pushing towards more information and imagery on their website. Strategy Director explained saying, "I'll be pushing the buyers now to adapt a lot more and since then, you need to come back from suppliers with content. You need to come back with imagery and you need to come back with their story because if you don't come back with that, how can you sell that product online?"

\subsection{Integrated Promotions}

Promotion data must be shared and available across all channels and the product's/brand's name and logo should be consistent across all channels, and the promotions should use different channels at the same time [65]. During the pre-purchase stage, retailers can use services such as digital signage showing videos, real-time pricing and product information that can be integrated with social media feeds that display consumers' reviews next to the merchandise to build the trust. Retailers can also use connected home appliances to sense customer needs and send personalized need-based offers through the mobile channel [29]. During the purchase stage of the consumer buying process, retailers can use consumer-facing in-store technology to inspire and engage 
with the consumer using different channels and offering personalized offers and promotions [35]. Burberry, M\&S, Nike and Macy's, for instance, have adopted interactive screens (e.g. iPads, i-Kiosks, tablet computers) through which consumers get promotions during the purchase stage. Besides, adaptive digital touchpoints enable new forms of promotions. For example, by introducing firm-initiated mobile touchpoints, retailers can "provide tailored, time-sensitive, and location-sensitive advertising and promotions in store" [21].

$\mathrm{CR}$ is working on integrating its promotion activities across different channels. They are actively targeting the integration of their social media channels with their website. Marketing Manager commenting on their priorities said ".. and just integrating better with our social media campaigns. I think there is a big disconnect there."

\subsection{Integrated Reverse Logistics}

Integrated reverse logistics entails providing all channels for returns to customers and return visibility in all channels as well [55]. Integrated reverse logistics links among different stages of reverse logistics and different channels involved in it. So, information around the return point(s), stock keeping point(s), and product(s) reverse flow should be retrievable, traceable, and changeable using RFID like M\&S [3]. retailers can easily provide services such as Buy online return in Store using RFID tagged products [69]. Retailers can, therefore, offer customers the ability to buy in-store and return via other channels such as using the website and get the return collected from their homes.

$\mathrm{CR}$ is providing the customers with the return to the store facility for products bought online but customers cannot return online (via post) the products bought in stores. Website Manager of CR said, "They [customers] can go into any of our stores and returns an online order if they have the receipt."

\subsection{Integrated Analytics}

Predicting customer needs and taking actions based on data available from all available channels is integrated analytics [29]. With different types of data available from various channels such as interaction data (POS, e-commerce), enterprise data (CRM and ERP) and unstructured data (social media data) which can be fused on one platform to predict customer intent and take informed actions [30]. At the same time, the route of each customer and the time they spend in different channels deciding what to purchase can be analyzed, similarly to the way it is analyzed by checking out the clicks on an e-shop browser. If combined with data, extracted by the e-shop web analytics application will allow the company to provide better and more accurate services and make product proposals, which can lead to a more gratifying interaction and raise sales [12]. Swatch and American Apparel have implemented successfully mobile tracking in their stores to track and analyze customer journeys in the store [11].

Strategy Director at CR put special emphasis on integrated analytics and capturing customer data in physical stores stating "capturing customer data [physical store customer] is a big one. And segmenting is going to make us so that we understand whether they're going to go online or whether they have the appetite to do so." 


\subsection{Integrated Data Security and Privacy}

Omnichannel retailers should ensure that the privacy conditions are adhered to when data is integrated from different channels. Consumers are concerned about how retailers can track their location and collect data about them, and how it affects their privacy. Retailers must be aware of privacy issues, seek to comply with the law first of all but also ethically use tracking and inform consumers about the type of information collected and its purpose. Appliances and sensors that upload a large quantity of personal data to centralized databases controlled by smart device manufacturers or retailers may be exposed to serious privacy problems [16]. Customers are becoming ever more concerned about their data privacy and retailer ensuring data privacy adds to the customers' perceived value and creating trustful customer relationships [29]. Integrated data security implies keeping customers' data secure when moved from one channel to another. With the implementation of digital devices to achieve integrated channel retailers are also facing the issue of data security. Overall, this information/knowledge flow should be protected by cybersecurity solutions to limit data theft and data misuse.

CR considers capturing the customer data as a vital step in the implementation of omnichannel strategy but privacy and security concerns are not well addressed. For example, talking about the implementation of a loyalty program, Strategy Director said “... and then absolutely the loyalty program again, I'll mention that I think we need to have a better connection to our customers physically like in terms of capturing their data and targeting them better."

\subsection{Integrated Fraud Detection}

Omnichannel retailing is more susceptible to frauds and needs an integrated fraud detection solution to address this new dynamic. Detecting fraud when a transaction involves more than one channel is integrated fraud detection. With digital and interconnected devices for channel integration, cyber-attacks become likely as the mobile and internet of things (IoT) devices have limited computing power to detect such attacks [66].

$\mathrm{CR}$ is not considering an increased risk of fraud associated with omnichannel at the time of the case study.

\section{Enabling Technologies for Channel Integration in Retail}

Multiple digital technologies are required to achieve total channel integration in retail [47]. According to the value chain model by Porter [52], technology development is one of the supporting activities for any organization. Also, staying current with technological advances, and maintaining technical excellence are sources of value creation. Thus, it is necessary to clearly identify the most relevant technologies and solutions to support the retailers in the transition towards the total channel integration to become omnichannel [4]. The role of digital technologies to facilitate channel integration activities identified in section 3 are explained in this section. In Table 1, these relevant technologies are described. In Table 2, real-world implementation examples are presented. 
Table 1. Description of Enabling Technologies for Channel Integration in Retail

\begin{tabular}{|c|c|}
\hline Enabling Technologies & Description \\
\hline Augmented Reality & $\begin{array}{l}\text { Augmented reality integrates computer-gener- } \\
\text { ated objects with the real environment and al- } \\
\text { lows real-time interactions. [32] }\end{array}$ \\
\hline Blockchain & $\begin{array}{l}\text { Blockchain technology consists of blocks that } \\
\text { are linked through cryptography. [1] }\end{array}$ \\
\hline Artificial Intelligence (AI) & $\begin{array}{l}\text { AI augments human intelligence and for the con- } \\
\text { text of this study, AI refers to machine learning, } \\
\text { natural language processing, drones and other AI } \\
\text { based systems. [20] }\end{array}$ \\
\hline Cloud Computing & $\begin{array}{l}\text { Cloud computing allows sharing of IT software } \\
\text { and hardware resources over the internet, so that } \\
\text { information can be easily stored and accessed re- } \\
\text { motely by diverse actors. [4] }\end{array}$ \\
\hline Internet of Things (IoT) & $\begin{array}{l}\text { IoT is a sophisticated network of objects and } \\
\text { things connected to the internet. The concept of } \\
\text { IoT in retail consists of Radio Frequency Identi- } \\
\text { fication (RFID), beacons, camera networks, and } \\
\text { other wireless sensor networks. [6] }\end{array}$ \\
\hline Mobile Technologies & $\begin{array}{l}\text { Mobile technologies refer to a set of technologies } \\
\text { related to smartphones including mobile apps, } \\
\text { scan and go, QR codes, location-based apps, etc. } \\
{[20]}\end{array}$ \\
\hline Biometric Technologies & $\begin{array}{l}\text { Biometric technologies are automated methods } \\
\text { of verifying or recognizing the identity of a per- } \\
\text { son based on their physiological or behavioral } \\
\text { characters. [61] }\end{array}$ \\
\hline Edge Computing & $\begin{array}{l}\text { Edge computing refers to the enabling technolo- } \\
\text { gies allowing computation to be performed at the } \\
\text { edge of the network, on downstream data and up- } \\
\text { stream data. [56] }\end{array}$ \\
\hline
\end{tabular}

Augmented Reality applications narrow the gap between online and offline shopping. They provide a sense of embodiment that results from natural interactivity and simulation of physical control over virtual offerings and sometimes exceeds what is possible in physical environments [25]. It is being used by firms like IKEA [32] to provide better product information (integrated product and price information). Mister Spex, is providing by using an AR virtual mirror an experience where customers can virtually try on different glasses from their online assortment. Walgreens offers its customers "Aisle411" application to receive digital way-finding support that helps them locate products in the supermarket aisle (integrated customer service) [25]. 
Blockchain offers attractive security features for distributed data processing and storage, especially when used with edge computing (Data Security and Data Privacy). Such systems are being implemented and developed in other industries such as health services. For example, using hierarchical identity-based cryptography for the handshake scheme. This scheme named as a cross-domain handshake (CDHS) scheme can be used to increase data security within integrated channels (integrated data security and privacy). Blockchain features can also be used for ensuring safe delivery to customers (integrated order fulfillment).

AI tools like machine learning extract the knowledge that is actually important in an omnichannel network. It helps the retailer to make sense of data by the transformation of raw data into information and then information to knowledge (integrated analytics) $[4,30]$. AI-based fraud detection solutions like the ones proposed by [26] can be used for detecting point of sales (POS) fraud when the system is integrated with other channels. Delivery technology based on AI such as drones facilitates the fulfillment process (integrated fulfillment). Facial recognition systems based on biometric technology are being used for identity verification e.g. Alibaba "pay with a selfie" (integrated transactions) [57]. However, the use of biometric technologies in retail is significantly affected by regulations such as GDPR in EU [46]. Methods of using biometric technologies must evolve for compliance to GDPR and sophisticated AI systems which can ensure the anonymity of the personal data processed can be a possible solution.

Cloud computing is devoted to storing raw data in structured information. Such information can be accessed by and exchanged between different channels, which may, in turn, use the structured information as the input for data analytics (integrated analytics) and customer assistant (integrated customer service) [4]. Cloud services also manage all types of raw data, but with the aim of storing structured information that may be helpful for logistics (integrated order fulfillment). Cloud computing based services can manage a multidirectional flow of information that can be used to support multiple activities like integrated product and price information, integrated promotions. Edge computing for IoT with blockchain can provide a transparent and secure alternative framework for private data management in the digitally enabled physical stores (integrated data security and privacy) [66].

IoTs play a vital role in multiple channel integration activities [15]. IoT solutions can be employed by retailers to acquire several types of data (e.g. the location of a component/product, customer data). Thereby, the data flow underlying IoTs combined with machine learning ( $\mathrm{AI}$ ) becomes a powerful resource for retailers to use for customer profiling (Integrated Analytics) and providing real-time recommendations (integrated customer service) [6]. Business to Thing Management based on IoTs can facilitate direct interactions with smart things and thus need-based promotions to the customer (integrated promotions). Edge computing is a viable way to take advantage of the explosion of the Internet of Things (IoT) which has dramatically increased the data load on networks. Integration of complex sensors, with the implementation of an efficient data fusion strategy can be used for integrated analytics and integrated customer traceability [37]. 
Beacon is an IoT based technology that allows retailers to send messages or notifications to consumers in the beacon's zone to promote specific products (integrated promotions) or give recommendations (integrated customer service) [18, 35]. It is used by retailers such as Macy's, Zara and H\&M for communications purposes with consumers [18]. Google announced the Physical Web initiative utilizing Bluetooth beacons as an IoT gateway and proximity-based service without the need for mobile apps. Beacon gateway can be used for analyzing data from customer movements in-store (integrated analytics). Data for tracing customers can be collected using software sensors (IoT) and smartphones (Integrated Customer Traceability). RFID is being used to track products in a store and during the delivery (integrated order fulfillment) as well from a distance by using tiny microchips hooked up to miniature antennas (integrated reverse logistics) [27]. Retailers can use RFID to locate store inventory, keep track of inventory and products on the delivery route [11]. By using RFID retailers can provide customized marketing programmes (Integrated promotions) for the customers at an individual level and hence increases product and brand awareness (integrated product and price information) [40].

Mobile technology is one of the main enablers of omnichannel realization [7]. To provide services such as zero check out vision systems can be combined with other technologies and provide integrated customer service. The touchscreen functionality of mobile devices can also be exploited for reducing the physical-digital divide between the in-store and online fashion shopping experience. The QR code, a two-dimensional matrix barcode, is a technology that is changing marketing in this decade. QR code can be used to provide integrated promotions and integrated products and price information. Using mobile ID tracking, retailers can use the consumers' smartphone's Wi-Fi to track their journey in the store and can know the repeat visitor and analyze the departments and parts of the store visited. Mobile Decision Support System can be used to check and compare reviews posted by consumers themselves and to extract reputations of a product from weblogs [21]. They might either retrieve data by scanning product barcodes or QR-codes with the mobile phone camera by using special m-shopping applications [21]. H\&M's have introduced a scan function in the mobile app that consumers can use in-store to scan the barcode of products and check their availability in other sizes and colors, as well as online promotions, personalized offers, and matching products.

Table 2. Overview of technologies and services for channel integration activities

\begin{tabular}{|l|l|l|}
\hline \multicolumn{1}{|c|}{$\begin{array}{c}\text { Channel Integration } \\
\text { Activity }\end{array}$} & $\begin{array}{c}\text { Enabling Tech- } \\
\text { nology }\end{array}$ & Examples of Implementation \\
\hline $\begin{array}{l}\text { Integrated Customer } \\
\text { Service }\end{array}$ & $\begin{array}{l}\text { Cloud Computing, } \\
\text { Augmented Real- } \\
\text { ity, Mobile Tech- } \\
\text { nology, AI }\end{array}$ & $\begin{array}{l}\text { Clarke's iPad feet measurement } \\
\text { [65], Digitally Enhanced cus- } \\
\text { tomer Assistant, Mobile Shop- } \\
\text { ping Assistant, Walmart Product } \\
\text { Finder, eBay Shopbot }\end{array}$ \\
\hline $\begin{array}{l}\text { Integrated Customer } \\
\text { Traceability }\end{array}$ & $\begin{array}{l}\text { Mobile Technolo- } \\
\text { gies }\end{array}$ & $\begin{array}{l}\text { Tesco's Virtual coupons [8], } \\
\text { Google Offline Attribution }\end{array}$ \\
\hline
\end{tabular}




\begin{tabular}{|c|c|c|}
\hline $\begin{array}{l}\text { Integrated Order Fulfil- } \\
\text { ment }\end{array}$ & IoT (RFID), AI & $\begin{array}{l}\text { Reserve and Pay [29], Click and } \\
\text { Collect [9, 39], Amazon Dash } \\
\text { Button [29], Amazon Key Deliv- } \\
\text { ery, Amazon Anticipatory Ship- } \\
\text { ping }\end{array}$ \\
\hline Integrated Promotion & $\begin{array}{l}\text { Mobile Technolo- } \\
\text { gies, Augmented } \\
\text { Reality, IoT (Bea- } \\
\text { con) }\end{array}$ & $\begin{array}{l}\text { Taggle, Viviono social commu- } \\
\text { nication [25], Mobile Mirror } \\
\text { [65], Location based recommen- } \\
\text { dations }\end{array}$ \\
\hline Integrated Transactions & $\begin{array}{l}\text { Mobile technolo- } \\
\text { gies, Biometric } \\
\text { Technologies }\end{array}$ & $\begin{array}{l}\text { Instagram Shopping [17], Ama- } \\
\text { zon Go [42], Uniqul Payment, } \\
\text { Alibaba 'Pay with Selfie' }\end{array}$ \\
\hline $\begin{array}{l}\text { Integrated Product and } \\
\text { Price Information }\end{array}$ & $\begin{array}{l}\text { Mobile Technolo- } \\
\text { gies, Augmented } \\
\text { Reality }\end{array}$ & $\begin{array}{l}\text { H\&M Scan and Buy, Bauble Bar } \\
\text { Interactive Display, Loreal } \\
\text { Makeup Genius [49], Nike's } \\
\text { product customization [25] }\end{array}$ \\
\hline $\begin{array}{l}\text { Integrated Reverse Lo- } \\
\text { gistics }\end{array}$ & IoT (RFID) & $\begin{array}{l}\text { Buy Online Return in Store, Re- } \\
\text { turn Collection from Home [15] }\end{array}$ \\
\hline Integrated Analytics & AI, IoT & $\begin{array}{l}\text { Video based emotion Analytics } \\
{[60]}\end{array}$ \\
\hline $\begin{array}{l}\text { Integrated Data Privacy } \\
\text { and Security }\end{array}$ & $\begin{array}{l}\text { Blockchain, Edge } \\
\text { Computing }\end{array}$ & $\begin{array}{l}\text { Automated access control man- } \\
\text { ager [70] }\end{array}$ \\
\hline $\begin{array}{l}\text { Integrated Fraud Detec- } \\
\text { tion }\end{array}$ & $\begin{array}{l}\text { AI, Biometric } \\
\text { Technologies }\end{array}$ & POS Fraud Detection [26] \\
\hline
\end{tabular}

\section{Research and Managerial Implications}

The findings from this research offer several insights for value creation through channel integration using digital technologies and add to information systems literature on ITenabled value creation [33]. The study investigates the extensive role of digital technologies in enabling value creation through channel integration in omnichannel retail [47]. A firm's value chain represents the linked activities that a firm executes to achieve effectiveness and efficiency. Performing value chain activities in ways that would give a firm the capability to outmatch rivals is a potential source of competitive advantage [52]. The value chain concept advocates that achieving competitive advantage begins with an effort to develop deeper organizational expertise in performing certain competitively critical value chain activities, deliberately attempting to harness those capabilities that strengthen the firm's strategy and competitiveness. This research tailors the value chain model [52] for omnichannel retailing and demonstrates how retailers can add value by utilizing appropriate technologies. Another important contribution of this study is the comprehensive analysis of the challenges faced by a retailer in execution of these activities. 
Several interesting practical findings have also emerged from this study. First, IoTs, mobile technologies and $\mathrm{AI}$ are required for most channel integration activities as shown in Table 3 but other technologies such as blockchain and edge computing can play a substantial role in creating value through channel integration. These are not required for numerous activities like the former but are very critical for the particular activities which they support. Edge computing is a viable way to take advantage of the explosion of IoTs which has dramatically increased the data load on networks. The integration of complex sensors, with the implementation of an efficient data fusion strategy, can be used for several services which leads to better service, more sales, and lower costs [35]. For example, [12] proposed an integrated analyzer for real time analytics for the physical store and online store using mobile technologies, communication techniques which are commonly used in e-commerce applications, thus supporting hybrid systems. This method offers much better service to customers of traditional brick and mortar shops. Another important finding from our study was that some services are being employed in other domains using the identified technologies which can be easily replicated in the retail sector but are not being implemented at the moment. For example, cross-domain handshake scheme being used in the healthcare sector can be used for data security during moving data from one channel to another. Similarly sophisticated machine learning is being used in financial services for fraud detection which can be easily adopted in retail. An ideal position for a retailer would be complete customer data integration (CDI) and a single view of the customer across channels. In the context of omnichannel retailers, facial recognition or other biometric technologies can be used as a unique identifier to identify customers across different channels but there are regulatory and cultural ramifications of using these technologies which must be taken into account. For example, biometric data can only be processed in EU if consent is given explicitly.

From a managerial perspective, our mapping framework can be used as a guideline to focus on technologies identified for certain aspects of channel integration to take advantage of the complementary role of all the channels. The retailers can identify the most important value chain activity for their strategy and start with technology selection and implementation for that particular activity. For example, if CR wants to start with integrated customer service, so by using our mapping guidelines they can zoom into mobile technologies, augmented reality, AI and cloud computing and the already successful implementation of these technologies by other retailers. Secondly, retailers need to build the internal capacity and capabilities to exploit the full potential of the aforementioned technologies to fully utilize the benefits of integrated channels [29, 38]. Retailers will only be able to implement most of the technologies (e.g. IoT, AI) if they have built the required capabilities to utilize these technologies. Retail managers must develop a systemic view of the use of digital technologies in order to better seize the current and future opportunities offered by channel integration. Some retailers (e.g. Amazon, Macy, H\&M, Zara) are using identified technologies to support some of the identified channel integration activities. Still, retailers are not taking full advantage of the benefits offered by these technologies for channel integration. For example, beacons have been mainly considered for fulfilling location-based customer experience and promotions but with beacon gateway, there is an aspect of using beacon technology for 
integrated analytics. Similarly, mobile technology is one of the main enablers of omnichannel realization [7] and its different features such as the touchscreen functionality of mobile devices can be exploited in various forms as means of reducing the physicaldigital divide between the in-store and online shopping experience [41].

\section{Conclusion}

This paper provides a comprehensive overview of the channel integration activities for an effective and efficient omnichannel value chain and the mapping of digital technologies to these activities. This study extends our knowledge on the omnichannel value chain and the use of digital technologies in retail. Underpinned by Porter's value chain model [52], we presented twofold guidelines for transformation of the retailers from multichannel to omnichannel. First, we identified the activities required for effective channel integration and the challenges faced in the execution of these activities. Secondly, we recognized the technologies and digital solutions that act as enablers for value creation. We also underlined examples of retail companies that have already attempted to integrate the channels using the identified technologies. In particular, the proposed examples reveal the important and complementary role those technologies play for channel integration.

Most of our attention has been devoted to the selection of technologies with the perspective of the current level of technologies. Future research could be done to analyze developing trends of the enabling technologies using techniques such as patent analysis. Relatedly, an assessment of the impact that the implementation of those technologies may have had on firm financial and operational performance should be further examined. There is also a need to test in detail specific solutions to further identify why companies are struggling with the implantation of the technology based solution for channel integration. In the presented omnichannel value chain model, we describe only the role of technologies as a support activity. Future research can elaborate on how firm structure, human resource management and procurement can support primary activities in the omnichannel value chain.

Acknowledgements. This research received funding from the European Union's Horizon 2020 research and innovation programme under the Marie Skłodowska- Curie grant agreement No. 765395 and supported in part by Science Foundation Ireland grant 13/RC/2094.

\section{References}

1. Aitzhan, N.Z., Svetinovic, D.: Security and privacy in decentralized energy trading through multi-signatures, blockchain and anonymous messaging streams. IEEE Trans. Dependable Secur. Comput. 15 (5), 840-852 (2018)

2. Angeles, R.: American apparel's journey towards accurate inventory management: Prelude to omnichannel retailing. In: Proceedings of the 11th IADIS International 
Conference Information Systems 2018, IS 2018. (2018)

3. Angeles, R.: Marks \& Spencer's RFID initiative: Laying the foundation for omnichannel retailing. In: Lecture Notes in Information Systems and Organisation. (2016)

4. Ardito, L., Petruzzelli, A.M., Panniello, U., Garavelli, A.C.: Towards Industry 4.0: Mapping digital technologies for supply chain management-marketing integration, (2018)

5. El Azhari, J., Bennett, D.: Omni-channel customer experience: an investigation into the use of digital technology in physical stores and its impact on the consumer's decisionmaking process. In: XXIV AEDEM International Conference, London, UK. (2015)

6. Balaji, M.S., Roy, S.K.: Value co-creation with Internet of things technology in the retail industry. J. Mark. Manag. 33 (1-2), 7-31 (2017)

7. Bank, J.: Integrating online and offline worlds through mobile technology in physical stores A quantitative study investigating the impact of. (2018)

8. Barnes, J.D., Distler, P.H.: Providing and tracking virtual coupons, (2016)

9. Bell, D.R., Gallino, S., Moreno, A.: How to win in an omnichannel world. MIT Sloan Manag. Rev. 56 (1), 45 (2014)

10. Blázquez, M.: Fashion Shopping in Multichannel Retail: The Role of Technology in Enhancing the Customer Experience. Int. J. Electron. Commer. 18 (4), 97-116 (2014)

11. Bonetti, F., Perry, P.: A Review of Consumer-Facing Digital Technologies Across Different Types of Fashion Store Formats. In: Advanced Fashion Technology and Operations Management. pp. 137-163. IGI Global (2017)

12. Boucouvalas, A.C., Aivalis, C.J., Gatziolis, K.: Integrating retail and e-commerce using web analytics and intelligent sensors. In: Communications in Computer and Information Science. (2016)

13. Vom Brocke, J., Simons, A., Niehaves, B., Riemer, K., Plattfaut, R., Cleven, A., others: Reconstructing the giant: On the importance of rigour in documenting the literature search process. In: Ecis. pp. 2206-2217. (2009)

14. Cao, L., Li, L.: The Impact of Cross-Channel Integration on Retailers' Sales Growth. J. Retail. (2015)

15. Caro, F., Sadr, R.: The Internet of Things (IoT) in retail: Bridging supply and demand. Bus. Horiz. 62 (1), 47-54 (2019)

16. Christidis, K., Devetsikiotis, M.: Blockchains and Smart Contracts for the Internet of Things, (2016)

17. Dariswan, P.P., Indriani, M.T.D.: Consumers' Attitude toward Shopping through Instagram Social Media. In: Proceedings of 7th Asia-Pacific Business Research Conference. pp. 25-26. (2014)

18. Fernie, J., Grant, D.B.: Fashion logistics: Insights into the fashion retail supply chain. Kogan Page Publishers (2015)

19. Franco, P.P.: Digital Retail and How Customer-Centric Technology is Reshaping the Industry: IT-Enabled Digital Disruption. In: Digital Multimedia: Concepts, Methodologies, Tools, and Applications. pp. 1560-1580. IGI Global (2018)

20. Grewal, D., Roggeveen, A.L., Nordfält, J.: The Future of Retailing. J. Retail. (2017)

21. Groß, M.: Mobile shopping: A classification framework and literature review. Int. J. Retail Distrib. Manag. (2015) 
22. Gudanowska, A.E.: Technology mapping--proposal of a method of technology analysis in foresight studies. Bus. Theory Pract. 17243 (2016)

23. Herhausen, D., Binder, J., Schoegel, M., Herrmann, A.: Integrating Bricks with Clicks: Retailer-Level and Channel-Level Outcomes of Online-Offline Channel Integration. J. Retail. 91 (2, SI), 309-325 (2015)

24. Heuchert, M., Barann, B., Cordes, A.-K., Becker, J.: An IS Perspective on OmniChannel Management along the Customer Journey: Development of an EntityRelationship-Model and a Linkage Concept. Multikonferenz Wirtschaftsinformatik. 435-446 (2018)

25. Hilken, T., Heller, J., Chylinski, M., Keeling, D.I., Mahr, D., de Ruyter, K.: Making omnichannel an augmented reality: the current and future state of the art. J. Res. Interact. Mark. 12 (4, SI), 509-523 (2018)

26. Hines, C., Youssef, A.: Machine Learning Applied to Point-of-Sale Fraud Detection. In: International Conference on Machine Learning and Data Mining in Pattern Recognition. pp. 283-295. (2018)

27. Hinkka, V., Häkkinen, M., Främling, K.: Typology of configurable RFID tracking in fashion logistics. Int. J. RF Technol. Res. Appl. (2015)

28. Hong, D.: Omnichannel Knowledge Series The Omnichannel Dilemma. (2015)

29. Hosseini, S., Röglinger, M., Schmied, F.: Omni-Channel Retail Capabilities: An Information Systems Perspective. 38th Int. Conf. Inf. Syst. . 4801 1-19 (2017)

30. Iftikhar, R., Khan, M.S.: Social Media Big Data Analytics for Demand Forecasting: Development and Case Implementation of an Innovative Framework. J. Glob. Inf. Manag. (JGIM. 28 (1), (2020)

31. Inman, J.J., Nikolova, H.: Shopper-Facing Retail Technology: A Retailer Adoption Decision Framework Incorporating Shopper Attitudes and Privacy Concerns. J. Retail. 93 (1, SI), 7-28 (2017)

32. Juny, T., tom Dieck, M.C.: Augmented Reality and Virtual Reality. (2018)

33. Kohli, R., Grover, V.: Business value of IT: An essay on expanding research directions to keep up with the times. J. Assoc. Inf. Syst. 9 (1), 1 (2008)

34. Larsen, N.M., Sigurdsson, V., Breivik, J.: The Use of Observational Technology to Study In-Store Behavior: Consumer Choice, Video Surveillance, and Retail Analytics. Behav. Anal. 40 (2), 343-371 (2017)

35. Lemon, K.N., Verhoef, P.C.: Understanding Customer Experience Throughout the Customer Journey. J. Mark. 80 (6), 69-96 (2016)

36. Lewis, J., Whysall, P., Foster, C.: Drivers and Technology-Related Obstacles in Moving to Multichannel Retailing. Int. J. Electron. Commer. 18 (4), 43-67 (2014)

37. Li, H., Shou, G., Hu, Y., Guo, Z.: Mobile edge computing: progress and challenges. In: Mobile Cloud Computing, Services, and Engineering (MobileCloud), 2016 4th IEEE International Conference on. pp. 83-84. (2016)

38. Luo, J., Fan, M., Zhang, H.: Information Technology, Cross-Channel Capabilities, and Managerial Actions: Evidence from the Apparel Industry. J. Assoc. Inf. Syst. 17 (5), 308-327 (2016)

39. Ma, H., Su, Y., Oh, L.-B.: Assessing multi-channel consumers' convenience expectations of online order/in-store pickup service. Int. J. Netw. Virtual Organ. 12. 14 (1-2), 146-159 (2014) 
40. Madhani, P.M.: Business value added through RFID deployment in retail: A synthesis, conceptual framework and research propositions. Int. J. Electron. Cust. Relatsh. Manag. (2011)

41. McCormick, H., Cartwright, J., Perry, P., Barnes, L., Lynch, S., Ball, G.: Fashion retailing - Past, present and future. Text. Prog. (2014)

42. McFarland, M.: Amazon Go: No cashiers, hundreds of cameras, and lots of data - CNN, 2018, https://edition.cnn.com/2018/10/03/tech/amazon-go/index.html, Accessed: March 26, 2019, (2018)

43. Mladenow, A., Mollova, A., Strauss, C.: Mobile technology contributing to omnichannel retail. In: ACM International Conference Proceeding Series. pp. 92-101. (2018)

44. Mosquera, A., Olarte-Pascual, C., Juaneda Ayensa, E., Sierra Murillo, Y.: The role of technology in an omnichannel physical store. Spanish J. Mark. - ESIC. 22 (1), 63-82 (2018)

45. Mou, S., Robb, D.J., DeHoratius, N.: Retail store operations: Literature review and research directions, (2018)

46. Nabbosa, V., Iftikhar, R.: Digital Retail Challenges within the EU : Fulfillment of Holistic Customer Journey post GDPR. In: 3rd International Conference on EEducation, E-Business and E-Technology. ACM, Madrid (2020)

47. Oh, L.-B., Teo, H.-H., Sambamurthy, V.: The effects of retail channel integration through the use of information technologies on firm performance. J. Oper. Manag. 30 (5), 368-381 (2012)

48. Orendorff, A.: Omni-Channel Retail Strategy: What, Why, and How, 2018, https://www.shopify.com/enterprise/omni-channel-retail-strategy, Accessed: November 06, 2018, (2018)

49. Parise, S., Guinan, P.J., Kafka, R., College, B., Hall, B., Park, B., Systems, C., Francisco, S., Area, B.: Solving the crisis of immediacy: How digital technology can transform the customer experience. Bus. Horiz. 59 (4), 411-420 (2016)

50. Pierdicca, R., Liciotti, D., Contigiani, M., Frontoni, E., Mancini, A., Zingaretti, P.: Low cost embedded system for increasing retail environment intelligence. In: 2015 IEEE International Conference on Multimedia and Expo Workshops, ICMEW 2015. (2015)

51. Piotrowicz, W., Cuthbertson, R.: Introduction to the Special Issue Information Technology in Retail: Toward Omnichannel Retailing. Int. J. Electron. Commer. (2014)

52. Porter, M.E.: Competitive advantage: Creating and sustaining superior performance. Simon and Schuster (2008)

53. Rigby, D.: The future of shopping. Harv. Bus. Rev. 89 (12), 65-76 (2011)

54. Rossignoli, C., Virili, F., Za, S.: Digital technology and organizational change: Reshaping technology, people, and organizations towards a global society. (2018)

55. Saghiri, S., Wilding, R., Mena, C., Bourlakis, M.: Toward a three-dimensional framework for omni-channel. J. Bus. Res. 77 (March), 53-67 (2017)

56. Shi, W., Cao, J., Zhang, Q., Li, Y., Xu, L.: Edge computing: Vision and challenges. IEEE Internet Things J. 3 (5), 637-646 (2016)

57. Smith, G.: Alibaba's Jack Ma shows off new 'pay with a selfie'technology, (2015)

58. Souiden, N., Ladhari, R., Chiadmi, N.E.: New trends in retailing and services. J. Retail. Consum. Serv. (xxxx), (2018)

59. Spiegel, J.R., McKenna, M.T., Lakshman, G.S., Nordstrom, P.G.: Method and system 
for anticipatory package shipping, (2013)

60. Tian, C., Zhang, R., Zhang, C., Zhao, X.: Intelligent Consumer Flow and Experience Analysis System Based on Cognitive Intelligence: Smart Eye System. In: Tseng, J and Kotenko, I. (ed.) 3rd Annual International Conference on Information System and Artificial Intelligence (ISAI2018). (2018)

61. Tripathi, K.P.: A comparative study of biometric technologies with reference to human interface. Int. J. Comput. Appl. 14 (5), 10-15 (2011)

62. Vazquez, D., Dennis, C., Zhang, Y.: Understanding the effect of smart retail brand Consumer communications via mobile instant messaging (MIM) - An empirical study in the Chinese context. Comput. Human Behav. 77 425-436 (2017)

63. Wang, R.J.H., Malthouse, E.C., Krishnamurthi, L.: On the Go: How Mobile Shopping Affects Customer Purchase Behavior. J. Retail. (2015)

64. Webster, J., Watson, R.T.: Analyzing the past to prepare for the future: Writing a literature review. MIS Q. xiii--xxiii (2002)

65. Willems, K., Smolders, A., Brengman, M., Luyten, K., Schöning, J.: The path-topurchase is paved with digital opportunities: An inventory of shopper-oriented retail technologies. Technol. Forecast. Soc. Change. (2017)

66. Xiong, Z., Zhang, Y., Niyato, D., Wang, P., Han, Z.: When mobile blockchain meets edge computing. IEEE Commun. Mag. (2018)

67. Yan, R., Wang, J., Zhou, B.: Channel integration and profit sharing in the dynamics of multi-channel firms. J. Retail. Consum. Serv. (2010)

68. Yin, R.K.: Case study research and applications: Design and methods. Sage publications (2017)

69. Zhang, M., Ren, C., Wang, G.A., He, Z.: The impact of channel integration on consumer responses in omni-channel retailing: The mediating effect of consumer empowerment. Electron. Commer. Res. Appl. 28 181-193 (2018)

70. Zyskind, G., Nathan, O., others: Decentralizing privacy: Using blockchain to protect personal data. In: 2015 IEEE Security and Privacy Workshops. pp. 180-184. (2015) 